\title{
1. AOTrauma-Prinzipien-Kurs für OP-Personal in Leipzig
}

Alexander Motzny

Nach langer Zeit fand am 25. und 26. September 2017 wieder ein AOTrauma-BasisKurs für OP-Personal im Osten Deutschlands statt. Die Ehre gebührte Leipzig, die Leitung hatten Professor Josten, Dr. Theopold, Dr. Brand und Alexander Motzny.

Neben Vorträgen zu allgemeinen Prinzipien der Frakturbehandlung und -heilung und zum Design und der Funktion von Platten und Schrauben wurden in verschiedenen Modulen zur relativen und absoluten Stabilität, der Winkelstabilität, der externen Osteosynthese, der Marknagelosteosynthese bei Schaftfrakturen, der Osteosynthese von Gelenkfrakturen und den Frakturen des proximalen Femurs in Diskussionsgruppen Wissen erarbeitet und vermittelt, sowie dazu praktische Übungen am Kunstknochen durchgeführt.
Andere Themen, wie die Anatomie des Knochens, Infektionsprophylaxe, „Wie lese ich Röntgenbilder“, Implantatentfernung und „Was bietet AOTrauma“ rundeten das Programm ab.

Die Teilnehmer arbeiteten mit großer Disziplin, Engagement und Interesse. Nur so war es möglich, dass das sehr straffe Programm reibungslos und zeitgenau durchgeführt werden konnte. Hierfür sei allen im Namen der Organisation allen Beteiligten großer Respekt gezollt.

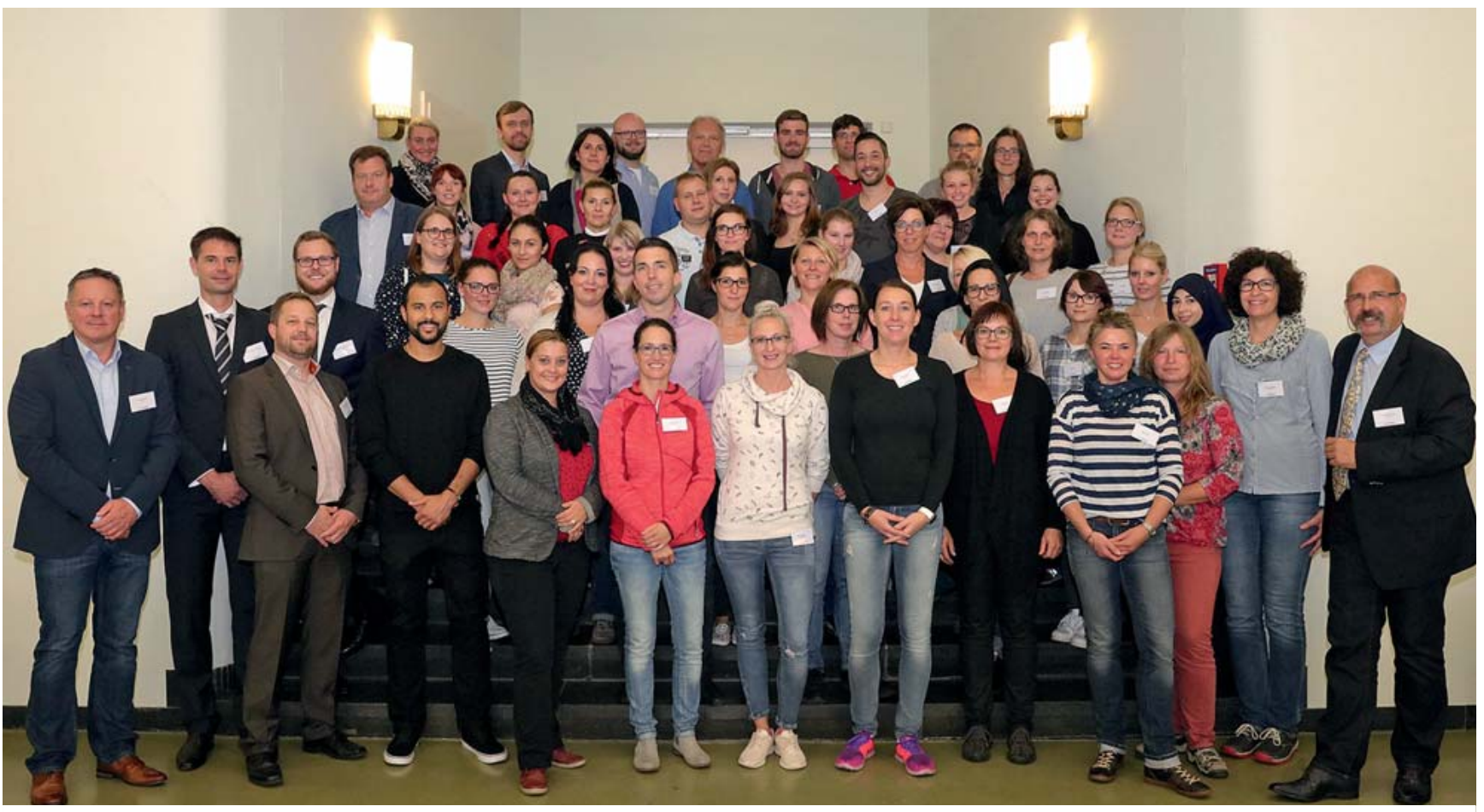

- Abb. 1 Gruppenfoto des Kurses. Bild: Alexander Motzny 


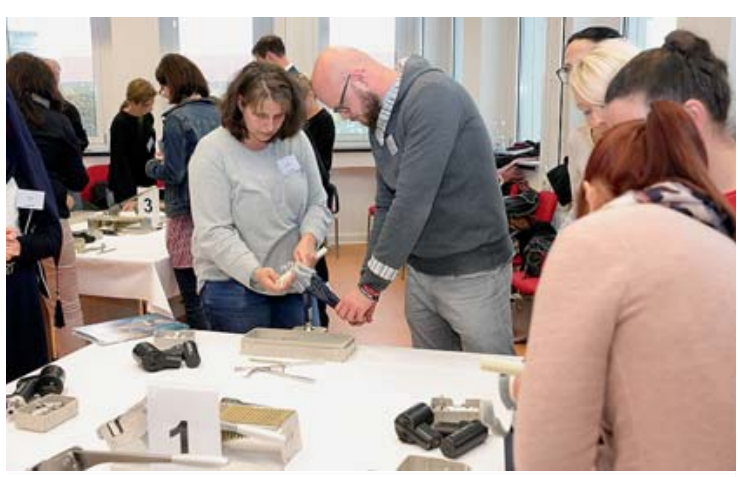

Abb. 2 Praktische Übungen. Bild: Alexander Motzny

Auch 2018 wird ein AOTrauma-Basis-Kurs für OP-Personal im Osten stattfinden: im September in Dresden unter der Leitung von Prof. Schaser. Dazu sind alle interessierten OP-Pflegekräfte herzlich eingeladen.

Alexander Motzny, Tübingen

Bibliografie

DOI https://doi.org/10.1055/a-0591-2485

OP-JOURNAL 2018; 34: 72-73 @ Georg Thieme Verlag KC

Stuttgart · New York ISSN 0178-1715 